\title{
Symposium on 'Phytochemicals'
}

\section{Biological effects of fruit and vegetables}

\author{
Lars O. Dragsted ${ }^{1,2 *}$, Britta Krath ${ }^{1}$, Gitte Ravn-Haren ${ }^{1}$, Ulla B. Vogel ${ }^{3}$, Anne Marie Vinggaard, Per Bo \\ Jensen $^{1}$, Steffen Loft ${ }^{2}$, Salka E. Rasmussen ${ }^{1}$, the late BrittMarie Sandstrom ${ }^{4}$ and Anette Pedersen ${ }^{4}$ \\ ${ }^{1}$ Danish Institute for Food and Veterinary Research, Soborg, Denmark \\ ${ }^{2}$ Department of Public Health, Panum Institute, University of Copenhagen, Copenhagen, Denmark \\ ${ }^{3}$ National Institute of Occupational Health, Copenhagen, Denmark \\ ${ }^{4}$ Research Department of Human Nutrition and Center for Advanced Food Studies, Royal Veterinary and Agricultural \\ University, Frederiksberg, Denmark
}

\begin{abstract}
A strong and persistent effect of plant-derived foods on the prevention of lifestyle diseases has emerged from observational studies. Several groups of constituents in plants have been identified as potentially health promoting in animal studies, including cholesterol-lowering factors, antioxidants, enzyme inducers, apoptosis inducers etc. In human intervention studies the dose levels achieved tend to be lower than the levels found to be effective in animals and sampling from target organs is often not possible. A controlled dietary human intervention study was performed with forty-three volunteers, providing $600 \mathrm{~g}$ fruit and vegetables/d or in the controls a carbohydrate-rich drink to balance energy intake. Surrogate markers of oxidative damage to DNA, protein and lipids, enzymic defence and lipid metabolism were determined in blood and urine. It was found that a high intake of fruit and vegetables tends to increase the stability of lipids towards oxidative damage. Markers of oxidative enzymes indicate a steady increase in glutathione peroxidase (GPX1) activity in erythrocytes during intervention with fruit and vegetables but there is no effect on GPX1 transcription levels in leucocytes. No change occurs in glutathione-conjugating or -reducing enzyme activities in erythrocytes or plasma, and there are no effects on the transcription of genes involved in phase 2 enzyme induction or DNA repair in leucocytes. Fruit and vegetable intake decreases the level of total cholesterol and LDL-cholesterol, but does not affect sex hormones. In conclusion, it has been shown that total cholesterol and LDL-cholesterol, markers of peripheral lipid oxidation, and erythrocyte GPX1 activity are affected by high intakes of fruit and vegetables. This finding provides support for a protective role of dietary fruit and vegetables against CVD.
\end{abstract}

Fruit and vegetables: Protective effect: Lipoprotein oxidation: Glutathione peroxidase: LDL-cholesterol

A high intake of fruit and vegetables has been associated with a decreased risk of CVD and cancers at many sites, although the association with cancer is currently weakening (Bazzano et al. 2002; Johnsen et al. 2003; Riboli \& Norat, 2003; Hung et al. 2004). This evidence derives from human observational studies, whereas results from experimental chronic rodent feeding studies with single fruits, vegetables or herbs often result in strong protection (Dragsted et al. 1993). Neither of these study designs provides much mechanistic information. Plant foods contain very many bioactive components with a variety of actions in experimental systems that are potentially related to chronic disease prevention (Duthie et al. 2003; $\mathrm{Hu}$, 2003; Keck \& Finley, 2004). These components include several types of cell wall material and fibre that interact with the gut flora and biliary excretion to elicit local effects that maintain the gut mucosal lining, as well as systemic effects such as cholesterol lowering, effects on 
insulin sensitivity, lowering of blood pressure etc. ( $\mathrm{Hu}$, 2003; Young et al. 2005). Many low-molecular-weight components in plant foods have the ability to interact with receptors or response elements, which can change gene expression (Finley, 2003). Some responses may be classified as chemical defence, e.g. the decrease in radicalmediated damage, the induction of phase 1 and 2 enzymes and the induction of antioxidant enzymes involved in glutathione synthesis and glutathione-based redox reactions. Such actions have been documented for compounds found in Allium and Brassica species (Keck \& Finley, 2004). Other actions may be classified as repair, e.g. DNArepair, or as hormonal actions such as the effects elicited by many compounds in soyabean (Lechner et al. 2005).

Official recommendations for fruit and vegetable intake in many countries of the world urge an intake of four or more servings daily. In Denmark the slogan is 'six-a-day' and the campaign has been particularly successful in achieving $>50 \%$ increases in mean fruit and vegetable intakes since it was launched. In order to investigate the potential mechanisms associated with the benefits of fruit and vegetable intakes a fully dietary-controlled human intervention study has been performed that compared intakes at the Danish recommended level with a fruit-and-vegetable-free diet (Dragsted et al. 2004). Two control groups were used, one of which was only compensated for energy (carbohydrates) whereas the other was also compensated for most vitamins and minerals using a specially-prepared pill. A range of markers related to possible short-term effects of fruit and vegetables were investigated, including effects on serum cholesterol and lipids, effects on sex hormones, the activity and expression of defence enzymes as well as antioxidant effects.

\section{Materials and methods}

Study design

Study design, recruitment of subjects, diet compositions, food analyses, blood sampling and markers of antioxidant damage, enzyme activity, RNA isolation, cDNA synthesis, DNA damage and repair have been described previously (Vogel et al. 2002; Moller et al. 2003; Dragsted et al. 2004). Briefly, a $24 \mathrm{~d}$ controlled dietary human intervention study in a parallel design was conducted with fortythree free-living healthy normal-weight male and female volunteers aged 19-45 years (see Fig. 1). The subjects were randomised to three groups that all received the basic diet free from fruits and vegetables for $24 \mathrm{~d}$. For the first group the basic diet was supplemented with $600 \mathrm{~g}$ fruits and vegetables, for the second group the basic diet was supplemented with a daily energy supplement in the form of a drink $(1189 \mathrm{~kJ} / \mathrm{d}$ as mixed sugars and citrate) and a placebo pill containing no vitamins or minerals, while for the third group the energy drink was provided together with a mineral and vitamin supplement containing (mg) a daily dose of: $\mathrm{Ca} 180, \mathrm{Cu} 0 \cdot 4, \mathrm{Fe} 3, \mathrm{Mg} 65, \mathrm{Mn} \mathrm{1} \cdot 1, \mathrm{P} 150$, K 640, Zn 1·4, $\alpha$-tocopherol 3·3, ascorbate $150, \beta$-carotene 5 , thiamine $0 \cdot 3$, riboflavin $0 \cdot 4$, vitamin $\mathrm{B}_{6} 0 \cdot 6$, niacin 3 , pantothenic acid 1.7 , biotin $1.7 \mu \mathrm{g}$, folate $125 \mu \mathrm{g}$, phylloquinone $250 \mu \mathrm{g}$. Fasting blood samples and urine

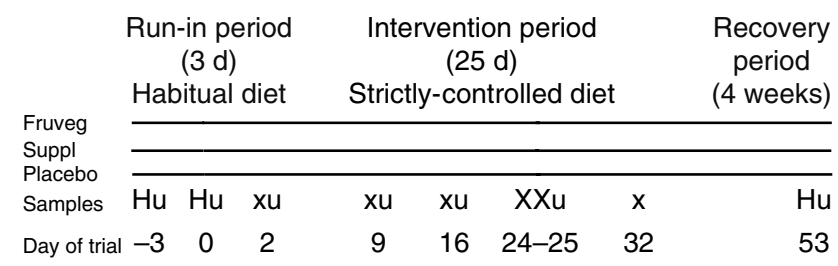

Fig. 1. Design of intervention study and sampling protocol. Fruveg, $600 \mathrm{~g}$ fruit and vegetables/d; placebo, placebo pill and no fruit and vegetables; suppl, vitamin and mineral pill (for details, see this page) and no fruit and vegetables; $\mathrm{H}$, habitual-diet blood samples; $\mathrm{x}$, intermediate blood samples; $\mathrm{X}$, final blood samples in the intervention period; u, a $24 \mathrm{~h}$ urine sample was collected. For details of subjects and procedures, see this page.

samples were collected before, during and after the intervention. The participants were all fully informed in writing about the study aim before they gave their consent to participate. The protocol was approved by the Ethics Committees of the municipalities of Copenhagen and Frederiksberg. Blood samples were collected at several time points, including two in the run-in period (days -3 and 0 ), three intermediate samples (days 2, 9 and 16), two samples at the end of intervention (days 24 and 25) and two samples post intervention (days 32 and 53). Urine samples were also collected at some of these time points (see Fig. 1). Biomarkers were analysed using minimum amounts of blood or urine sampled in the run-in period and at the end of intervention.

\section{Lipids and hormones}

Plasma total cholesterol and triacylglycerols and lipoprotein-cholesterol and triacylglycerol concentrations were measured before treatment and then monthly until the termination of the study using an automatic analyser (Hitachi 912; Roche Diagnostics, Mannheim, Germany), with a CV of $<3 \%$. Lipoproteins were separated by single-densitygradient ultracentrifugation for $18 \mathrm{~h}$ at $21^{\circ} \mathrm{C}$ (Terpstra et al. 1981).

Hormones were measured by time-resolved fluorescence using commercially-available fluorescence immunoassay kits (PerkinElmer Life Sciences, Turku, Finland).

\section{Primer and probe design}

Oligonucleotide primers and TaqMan $^{\circledR}$ probes were designed with Primer Express software v 1.5 (Applied Biosystems, Nærum, Denmark), based on sequences from the Genbank database (Table 1). Genomic DNA amplification was excluded whenever possible by designing the probes to cover a splice junction.

\section{mRNA quantification}

Real-time PCR was performed on an ABI PRISM ${ }^{\circledR}$ 7900HT Sequence Detection System (Applied Biosystems). The PCR reaction was determined in a final volume of $20 \mu \mathrm{l}$, adding $2 \mathrm{ng}$ cDNA, using TaqMan ${ }^{\circledR}$ Universal PCR Master Mix (Applied Biosystems). For each target gene $(\gamma$-glutamyl cysteinyl synthetase heavy chain, aryl hydrocarbon receptor repressor, glutathione peroxidase 
Table 1. Origin and design of primers and probes for expression analyses

\begin{tabular}{|c|c|c|c|}
\hline Gene & Genbank & Primer or probe & Sequence $5^{\prime}-3^{\prime}$ \\
\hline$G P X 1$ & AY327818 & $\begin{array}{l}\text { Sense } \\
\text { Antisense } \\
\text { TaqMan }{ }^{\mathbb{R}} \text { probe }\end{array}$ & $\begin{array}{l}\text { CCCGTGCAACCAGTTTGG } \\
\text { TGAGGGAATTCAGAATCTCTTCGT } \\
\text { 6-FAM-CATCAGGAGAACGCC-MGB }\end{array}$ \\
\hline$G C L C$ & $\begin{array}{l}\text { NM0001498 } \\
\text { M90656 }\end{array}$ & $\begin{array}{l}\text { Sense } \\
\text { Antisense } \\
\text { TaqMan }{ }^{\mathbb{R}} \text { probe }\end{array}$ & $\begin{array}{l}\text { CGGCACAAGGACGTTCTCA } \\
\text { ACCGGACTTTTTTATTTTCATGATCA } \\
\text { 6-FAM-CGATGAGGTGGAATAC-MGB }\end{array}$ \\
\hline Fra-1 & $\begin{array}{l}\text { BC016648 } \\
\text { NM005438 }\end{array}$ & $\begin{array}{l}\text { Sense } \\
\text { Antisense } \\
\text { TaqMan }{ }^{\mathbb{R}} \text { probe }\end{array}$ & $\begin{array}{l}\text { GCCGCCCTGTACCTTGTATC } \\
\text { CAGTGCCTCAGGTTCAAGCA } \\
\text { 6-FAM-CTTTCCCCAGGGCCT-MGB }\end{array}$ \\
\hline$A h R R$ & NM020731 & $\begin{array}{l}\text { Sense } \\
\text { Antisense } \\
\text { TaqMan }^{\circledR} \text { probe }\end{array}$ & $\begin{array}{l}\text { GAATCGGAACTGCATGGAAAA } \\
\text { CCAAAACGCCGCTCTCTCT } \\
\text { 6-FAM-CAATTACTCAGCAGGAAGG-MGB }\end{array}$ \\
\hline
\end{tabular}

GPX1, glutathione peroxidase 1; GCLC, $\gamma$-glutamylcysteine synthetase catalytic subunit; Fra-1, FOS-like antigen 1; AhRR, aryl-hydrocarbon receptor repressor; 6-FAM, 6-carboxyfluorescein; MGB, minor groove binding.

$(G P X)$ and Fra-1, the repressor of electrophile response element (EpRE) activation) the probe concentration was $0 \cdot 3 \mu \mathrm{M}$ and the primer concentrations were $0 \cdot 3 \mu \mathrm{M}$ for the detection of the $\gamma$-glutamyl cysteinyl synthetase heavy chain and aryl hydrocarbon receptor repressor genes, $0.5 \mu \mathrm{M}$ for $G P X$ and $0.9 \mu \mathrm{M}$ for Fra-1. 18S rRNA was selected as the endogenous control (Applied Biosystems) to correct for potential variation in RNA loading and the efficiency of the amplification reaction, and used as recommended by the manufacturer. The PCR amplification was performed in ninety-six-well plates in triplicate using the following cycling protocol: $50^{\circ} \mathrm{C}$ for $2 \mathrm{~min}, 95^{\circ} \mathrm{C}$ for $10 \mathrm{~min}$ and 45 cycles at $95^{\circ} \mathrm{C}$ for $15 \mathrm{~s}$ and $60^{\circ} \mathrm{C}$ for $1 \mathrm{~min}$. To confirm equal amplification efficiencies the criterion used was a regression slope of $<0 \cdot 1$ for each target gene normalised to $18 \mathrm{~S}$ rRNA, which confirmed that the comparative threshold cycle $(\mathrm{Ct})$ method for the relative quantification of target could be used without running standard curves on the same plate (data not shown). Briefly, the $\mathrm{Ct}$ is defined as the point at which the first significant increase in fluorescence is observed. The $\Delta \mathrm{Ct}$ value for each sample is the difference between $\mathrm{Ct}$ for the target gene and $\mathrm{Ct}$ for the endogenous control gene $18 \mathrm{~S}$ rRNA. Results are expressed as the fold difference in gene expression after intervention relative to the gene expression observed before intervention $(\Delta \Delta \mathrm{Ct})$, calculated using the formula: fold change $=2^{-\Delta \Delta C t}$. To further verify the specificity of PCR assays the PCR was performed with non-reverse-transcribed total RNA and samples lacking the DNA template. No significant amplifications were obtained in any of these samples (data not shown). Dayto-day variation in $\Delta \mathrm{Ct}$ of the control was $<3 \%$ for all genes.

\section{Statistics}

Data were analysed for homogeneity of variance using the Levenes test and for normal distribution using the ShapiroWilks W test, both with $P<0 \cdot 05$. Logarithmic transformation was used for data that did not meet these criteria. Paired $t$ tests were used to analyse changes between the run-in period (mean of days -3 and 0 ) and the end (mean of days 24 and 25) of the intervention. Changes over the course of the intervention and post-intervention were analysed using repeated-samples analysis of covariance with diet, gender and trial day as class variables and the run-in period values as covariates. Tukey's $t$ test was used to assess differences on specific days if analysis of covariance yielded a significant result. Data that did not meet the criteria for ANOVA or $t$ test analyses after transformation were tested by non-parametric Wilcoxon rank scores and Wilcoxon two-sample tests.

\section{Results}

The three intervention groups did not differ in relation to mean age (26.3 (sD 6.7) years), BMI $(23 \cdot 1$ (SD $\left.2 \cdot 2) \mathrm{kg} / \mathrm{m}^{2}\right)$, pre-intervention fruit intakes (290 (SD 170) g/d), energy intakes $(9660(\mathrm{SD} 3300) \mathrm{kJ} / \mathrm{d})$ or intakes of nutrients and micronutrients, as previously reported (Dragsted et al. 2004). Serum $\alpha$ - and $\beta$-carotene as well as plasma ascorbate were used to objectively assess compliance, and there were no indications of deviation from the provided diet (Dragsted et al. 2004).

Intervention with fruit and vegetables significantly $(P<0 \cdot 01)$ decreased total cholesterol and LDL-cholesterol after $24 \mathrm{~d}$ of intervention (Fig. 2). The decrease in total cholesterol was $10.8 \%$ and the change in LDL-cholesterol was $11.5 \%$ compared with baseline values. HDL-cholesterol also decreased $(9.5 \%)$, but the change was not significant. HDL-cholesterol:LDL-cholesterol did not change significantly (data not shown). The sex steroid hormones oestradiol and testosterone were apparently unaffected by the dietary changes and so were other sex hormones, including sex hormone-binding globulin, prolactin and luteinising hormone (Fig. 3).

It has previously been reported (Dragsted et al. 2004) that intervention does not affect erythrocyte enzyme activities of the antioxidant enzymes catalase and superoxide dismutase, whereas there is a time-dependent increase in the activity of GPX1. As seen in Fig. 4 the expression of the antioxidant selenoprotein gene GPXI in leucocytes was not significantly affected by the dietary 
(A)

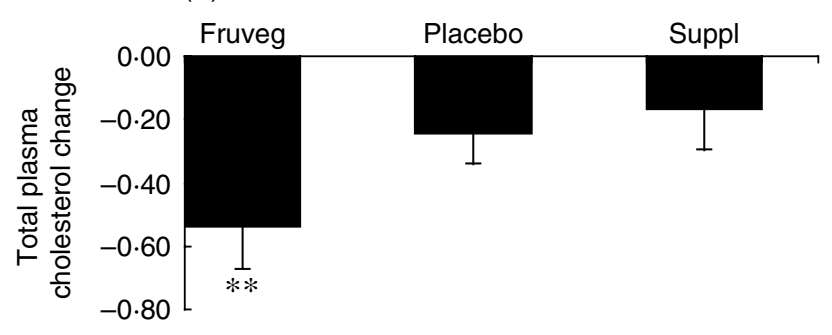

(B)

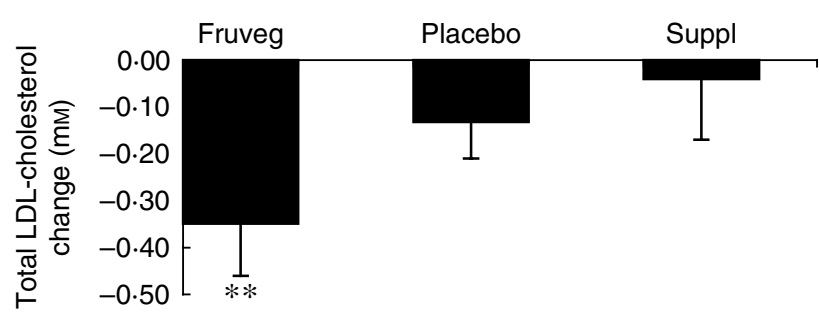

(C)

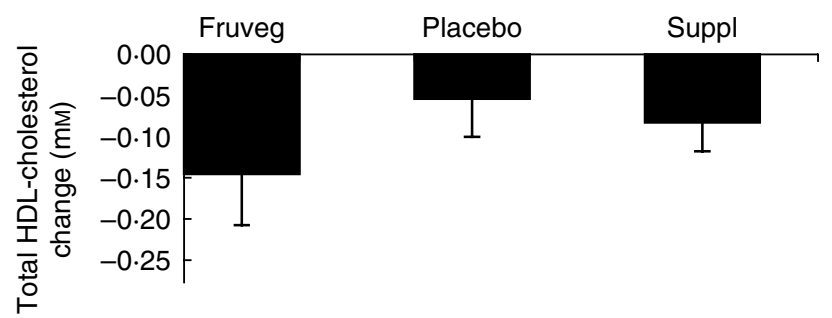

Fig. 2. Change (mm) in total cholesterol (A), LDL-cholesterol (B) and HDL-cholesterol $(C)$ between the run-in period and the end of the intervention for the three dietary intervention groups: fruveg, $600 \mathrm{~g}$ fruit and vegetables/d; placebo, placebo pill and no fruit and vegetables; suppl, vitamin and mineral pill (for details, see p. 62) and no fruit and vegetables. For details of subjects and procedures, see p. 62 and Fig. 1. Values are means with their standard errors represented by vertical bars. Mean values were significantly different from those for the two control groups: ${ }^{\star \star} P<0.01$.

changes, although an apparent time-dependent increase of $\leq 1 \cdot 5$-fold was recorded for the group consuming fruit and vegetables compared with a minor change for the two other groups, matching the changes observed in erythrocyte GPX activity. This apparent increase in expression was dependent on only two participants with large changes in GPXI expression during intervention. Erythrocyte glutathione-Stransferase and glutathione reductase activities were unaltered at all time points following intervention (Fig. 5). They may be induced through transactivation of EpRE sequences in their promoter regions or possibly also through the aryl hydrocarbon receptor pathway. Expression of the gene for the feedback repressor protein aryl hydrocarbon receptor repressor is controlled by the aryl hydrocarbon receptor as well as by expression of the EpRE feedback repressor gene Fra-l and the EpRE-inducible gene $\gamma$-glutamyl cysteinyl synthetase heavy chain, which were not significantly increased by any of the diets (Fig. 6), although the placebo intervention tended to increase both repressor genes.

\section{Discussion}

A high dietary intake of fruit and vegetables is associated with a decreased risk of CVD and cancer (Bazzano et al. 2003; Key et al. 2004). Recent prospective studies support the association with vascular diseases but are less consistent for several cancers (Hung et al. 2004; Vastag, 2005). It is hypothesised that fruit and vegetables may protect the organism against chronic disease by eliciting short-term protective effects in periods after fruit and vegetable intake, so that frequent intake may be necessary in order to have continued protection. The short-term protective effects may be antioxidant or redox effects, alterations in sterol metabolism, xenobiotic-metabolizing enzyme induction etc.; for example, the effects of redoxactive compounds would only last as long as the antioxidant or pro-oxidant reaches sufficient levels in blood and tissues. Some antioxidants, such as the catechins, are known to reach sufficient levels in plasma to change some markers of antioxidant capacity (Young et al. 2002). Catechins have short half-lives, in the range of $1 \mathrm{~h}$, whereas others such as the flavonol, quercetin and the anthocyanins have longer half-lives but are only poorly absorbed (Young et al. 1999; Nielsen et al. 2003). Markers of antioxidant capacity may serve to integrate the impact of many water-soluble plant food constituents with redox activities under physiological conditions. It has previously been reported (Dragsted et al. 2004) that markers of antioxidant capacity are not affected by the dietary interventions used in the present study. It has also been shown (Dragsted et al. 2005) that postprandial plasma samples have no increased antioxidant capacity. However, these markers are generally not as sensitive to antioxidants present in the lipid phase. LDL absorbs some lipophilic antioxidants, and the stability of this lipoprotein against ex vivo oxidation has been extensively used as a marker and has most often been associated with increased intakes of fruits and vegetables (Hininger et al. 1997; Bub et al. 2000; Chopra et al. 2000). Data on compliance markers from the present study have been published previously (Dragsted et al. 2004), and they indicate that participants adhered to the intervention diets. The compliance markers selected were water-soluble ascorbate and lipophilic $\beta$ carotene and lycopene, which are all redox active and could affect antioxidative resistance or oxidative damage in the body. Data on biomarkers of resistance or damage to protein, lipid and DNA have also been published (Vogel et al. 2002; Moller et al. 2003; Dragsted et al. 2004). These results indicate that dietary fruit and vegetables have an effect on the ex vivo resistance of LDL to oxidation, with a clear trend of increasing resistance through the intervention period. This finding might suggest that the more-lipophilic antioxidants are more important. There are no differences between treatment groups for $24 \mathrm{~h}$ urinary excretion of isoprostanes. Protein oxidation, as determined by total carbonyl formation, is also unaltered, whereas there is a decrease in oxidation at lysine residues of plasma proteins for the placebo intervention group, given neither fruit and vegetables nor vitamins and minerals (Dragsted et al. 2004). The time-course follows that of plasma ascorbate, in accordance with several previous results 
(A)

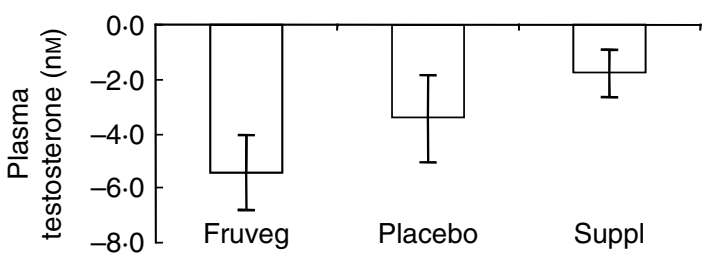

(C)

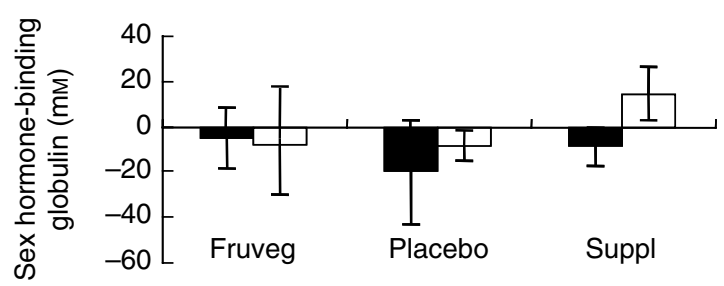

(B)

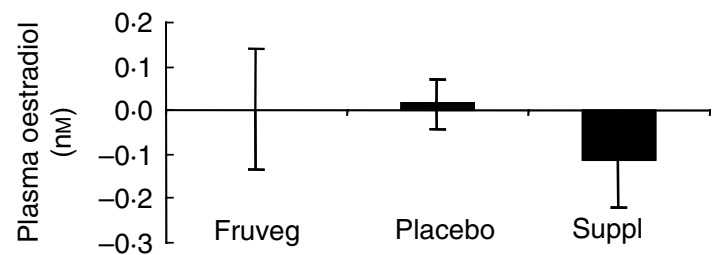

(D)

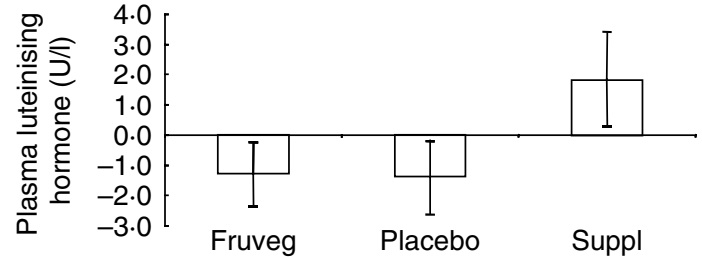

$(\mathrm{E})$

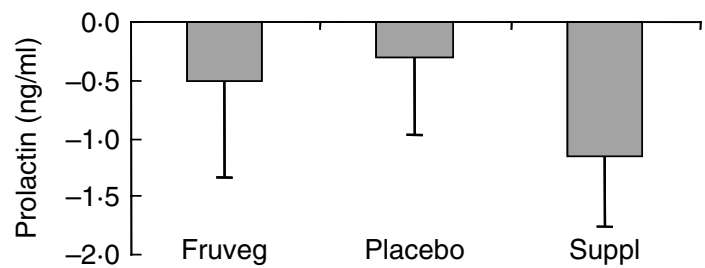

Fig. 3. Change in the plasma levels of sex hormones (A, testosterone; B, oestradiol; C, sex hormone-binding globulin; D, luteinising hormone; $E$, prolactin) between the run-in period and the end of the intervention for the three dietary intervention groups: fruveg, $600 \mathrm{~g}$ fruit and vegetables/d; placebo, placebo pill and no fruit and vegetables; suppl, vitamin and mineral pill (for details, see p. 62) and no fruit and vegetables. For details of subjects and procedures, see p. 62 and Fig. 1. ( $\square$ ), Males; $(\square)$, females; $(\square)$, both genders. Values are means with their standard errors represented by vertical bars. There were no significant differences between the groups.

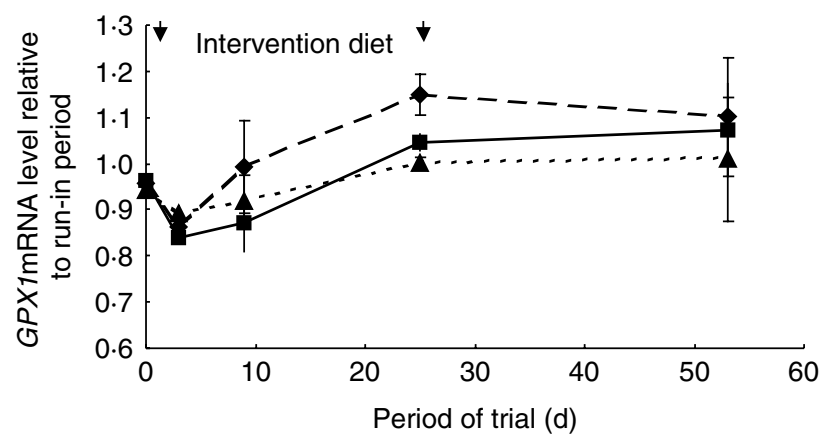

Fig. 4. Time-course of expression of glutathione peroxidase $(G P X 1)$ in leucocytes for the three dietary intervention groups: fruveg, $600 \mathrm{~g}$ fruit and vegetables/d $(\bullet)$; placebo, placebo pill and no fruit and vegetables (ם); suppl, vitamin and mineral pill (for details, see p. 62) and no fruit and vegetables ( $\mathbf{\Lambda})$. Values are means with their standard errors represented by vertical bars. $\downarrow$, The start and end of dietary interventions. For details of subjects and procedures, see p. 62 and Fig. 1. There were no significant differences between the groups (non-parametric test).

using this marker (Young et al. 2000, 2002). Thus, it appears that plasma redox actions caused by these dietary factors vary between compartments and may also depend on a certain oxidative challenge in order to be observable, at least in the lipid compartment. Whole-body oxidative damage to DNA and to free deoxyguanosine may be determined as changes in the steady-state urinary excretion of 8-oxo-deoxyguanosine, or specific damage to leucocyte DNA may be determined as strand breaks by the comet assay. It has been shown that neither of these markers is affected by the intervention diets used in the present study (Moller et al. 2003). GPX1 activity in erythrocytes is affected in a time- and diet-dependent manner, thus indicating that fruit and vegetables may increase the defence against peroxidation in this compartment (Dragsted et al. 2004). In the present study there is a similar trend in GPXI expression in leucocytes, but there are no significant differences in expression between the three diets by nonparametric tests. There are no changes in leucocyte expression of the genes $\gamma$-glutamyl cysteinyl synthetase heavy chain and Fra-1, which can be transactivated by the EpRE, or aryl hydrocarbon receptor repressor, which is regulated by the xenobiotic-response element. This finding is in accordance with the lack of change in erythrocyte glutathione-S-transferase activity reported previously (Dragsted et al. 2004).

The present study shows a significant $(P \leq 0 \cdot 01)$ decrease in total cholesterol and LDL-cholesterol of about $10 \%$, but also a non-significant decrease in HDL-cholesterol. A similar finding for total cholesterol and LDL-cholesterol has been reported (Singhal et al. 2001) in a $30 \mathrm{~d}$ randomised controlled trial among 175 patients with CHD after intervention with $400 \mathrm{~g}$ fruit and vegetables daily. In contrast to the findings of the present trial HDL-cholesterol 
(A)

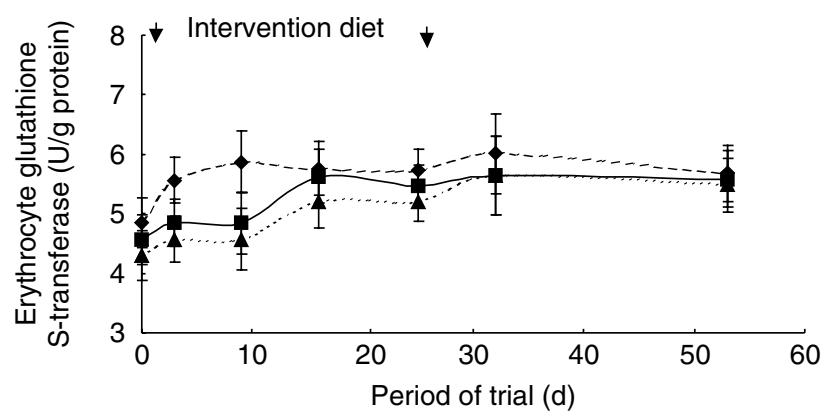

(B)

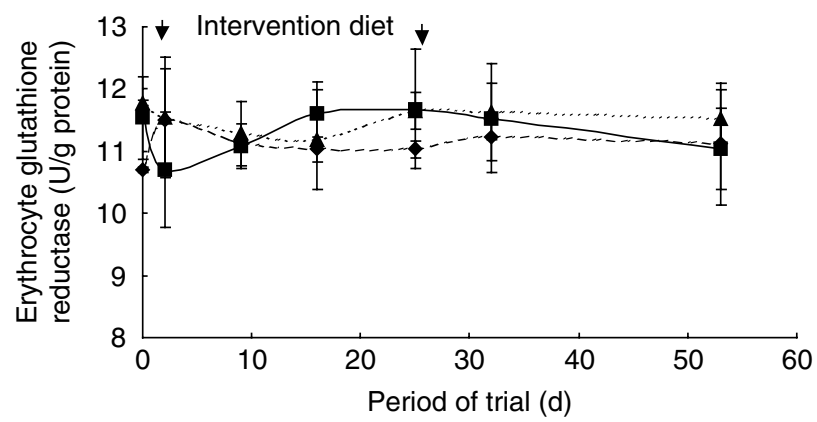

Fig. 5. Time-course in the activities of erythrocyte glutathioneS-transferase (A) and glutathione reductase (B) in the three dietary intervention groups: fruveg, $600 \mathrm{~g}$ fruit and vegetables $/ \mathrm{d}(\diamond)$; placebo, placebo pill and no fruit and vegetables (ם); suppl, vitamin and mineral pill (for details, see p. 62) and no fruit and vegetables $(\mathbf{\Delta})$.Values are means with their standard errors represented by vertical bars. $\downarrow$, The start and end of dietary interventions. For details of subjects and procedures, see p. 62 and Fig. 1. There were no significant differences between the groups (ANOVA).

was reported to increase. Differences in volunteer groups, duration of intervention, selection of fruit and vegetables for the intervention diets or other differences between the two studies may explain this discrepancy. Changes in effects on HDL-cholesterol have previously been noted in the Indian diet-heart single-blinded intervention study in which it was observed that increased intake of fruit tends to decrease HDL-cholesterol after 8 weeks (Singh et al. 1992b), whereas there is an increase after 12 weeks (Singh et al. 1992a). The changes in the present study may be explained by the $33 \%$ increase in fibre intake (from a mean of $15 \mathrm{~g} / \mathrm{d}$ in the groups receiving the placebo and the supplement to $20 \mathrm{~g} / \mathrm{d}$ in the group receiving fruit and vegetables) or by an increased intake of unidentified non-nutrient factors from fruit and vegetables such as plant sterols. Sex hormone levels were determined in order to assess whether the lowered cholesterol might be reflected in other aspects of sterol metabolism. The absence of effects on female oestradiol levels or male testosterone levels, or on plasma levels of the other sex hormones, including sex hormone-binding globulin, luteinising hormone and prolactin, indicates that no compensatory mechanisms may have influenced these results.

In conclusion, a controlled dietary intervention with fruit and vegetables has been shown to have significant effects on plasma lipoprotein oxidation, erythrocyte peroxide
(A)

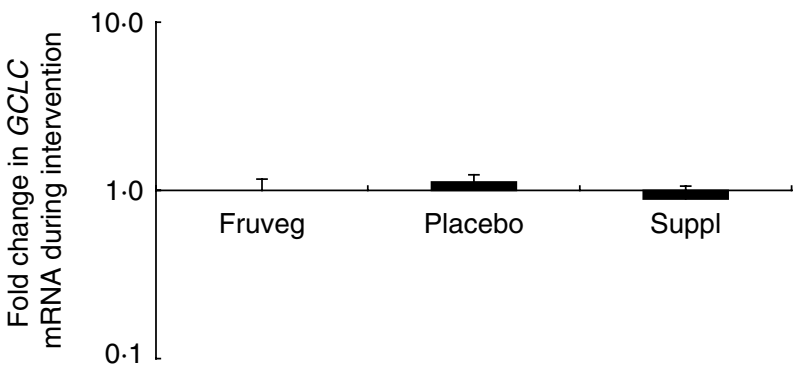

(B)

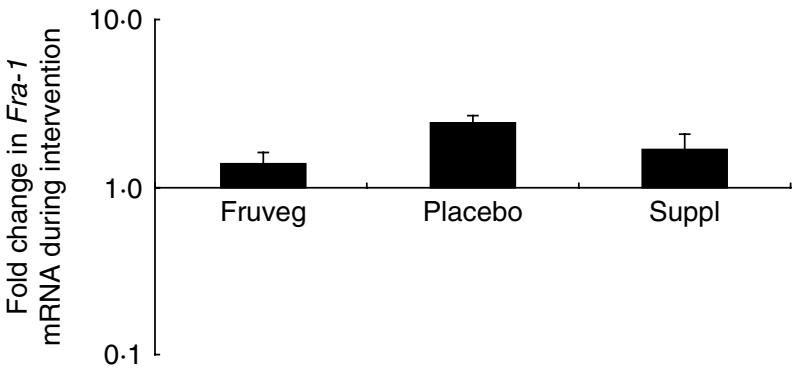

(C)

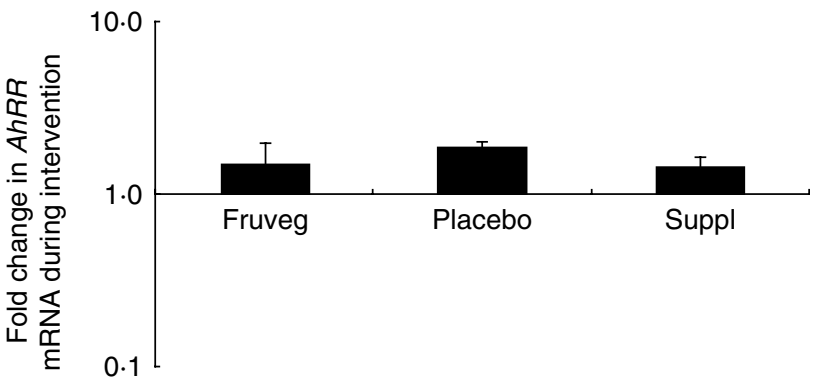

Fig. 6. Change in the expression (fold change in amounts of specific mRNA) of the repressor genes $\gamma$-glutamyl cysteinyl synthetase heavy chain (GCLC; A), Fra-1, the repressor of electrophile response element activation (B) and aryl hydrocarbon receptor repressor $(A h R R ; C)$ between the run-in period and the end of the intervention for the three dietary intervention groups: fruveg, $600 \mathrm{~g}$ fruit and vegetables/d; placebo, placebo pill and no fruit and vegetables; suppl, vitamin and mineral pill (for details, see p. 62) and no fruit and vegetables. For details of subjects and procedures, see p. 62 and Fig. 1. Values are means with their standard errors represented by vertical bars. There were no significant differences between the groups.

metabolism as well as serum LDL-cholesterol and total cholesterol. None of these effects are related to any of the vitamins or minerals present in the fruit and vegetable intervention. These findings are in good accordance with the increasing evidence that diets rich in fruit and vegetables have a protective effect against CVD and lend further support to dietary recommendations for an increased intake of fruit and vegetables.

\section{References}

Bazzano LA, He J, Ogden LG, Loria CM, Vupputuri S, Myers L \& Whelton PK (2002) Fruit and vegetable intake and risk 
of cardiovascular disease in US adults: the first National Health and Nutrition Examination Survey Epidemiologic Follow-up Study. American Journal of Clinical Nutrition 76, 93-99.

Bazzano LA, Serdula MK \& Liu S (2003) Dietary intake of fruits and vegetables and risk of cardiovascular disease. Current Atherosclerosis Reports 5, 492-499.

Bub A, Watzl B, Abrahamse L, Delincee H, Adam S, Wever J, Muller H \& Rechkemmer G (2000) Moderate intervention with carotenoid-rich vegetable products reduces lipid peroxidation in men. Journal of Nutrition 130, 2200-2206.

Chopra M, O'Neill ME, Keogh N, Wortley G, Southon S \& Thurnham DI (2000) Influence of increased fruit and vegetable intake on plasma and lipoprotein carotenoids and LDL oxidation in smokers and nonsmokers. Clinical Chemistry 46, 1818-1829.

Dragsted LO, Haren GR, Pedersen A, Hermetter A, Basu S, Hansen M et al. (2005) Answer to Serafini et al. American Journal of Clinical Nutrition 81, 532-534.

Dragsted LO, Pedersen A, Hermetter A, Basu S, Hansen M, Haren GR et al. (2004) The 6-a-day study: effects of fruit and vegetables on markers of oxidative stress and antioxidative defense in healthy nonsmokers. American Journal of Clinical Nutrition 79, 1060-1072.

Dragsted LO, Strube M \& Larsen JC (1993) Cancer-protective factors in fruits and vegetables: biochemical and biological background. Pharmacology and Toxicology 72, Suppl. 1, 116-135.

Duthie GG, Gardner PT \& Kyle JA (2003) Plant polyphenols: are they the new magic bullet? Proceedings of the Nutrition Society 62, 599-603.

Finley JW (2003) The antioxidant responsive element (ARE) may explain the protective effects of cruciferous vegetables on cancer. Nutrition Reviews 61, 250-254.

Hininger I, Chopra M, Thurnham DI, Laporte F, Richard M-J, Favier A \& Roussel A-M (1997) Effect of increased fruit and vegetable intake on the susceptibility of lipoprotein to oxidation in smokers. European Journal of Clinical Nutrition 51, 601-606.

Hu FB (2003) Plant-based foods and prevention of cardiovascular disease: an overview. American Journal of Clinical Nutrition 78, 544S-551S.

Hung HC, Joshipura KJ, Jiang R, Hu FB, Hunter D, SmithWarner SA, Colditz GA, Rosner B, Spiegelman D \& Willett WC (2004) Fruit and vegetable intake and risk of major chronic disease. Journal of the National Cancer Institute 96, $1577-1584$

Johnsen SP, Overvad K, Stripp C, Tjonneland A, Husted SE \& Sorensen HT (2003) Intake of fruit and vegetables and the risk of ischemic stroke in a cohort of Danish men and women. American Journal of Clinical Nutrition 78, 57-64.

Keck AS \& Finley JW (2004) Cruciferous vegetables: cancer protective mechanisms of glucosinolate hydrolysis products and selenium. Integrative Cancer Therapies 3, 5-12.

Key TJ, Schatzkin A, Willett WC, Allen NE, Spencer EA \& Travis RC (2004) Diet, nutrition and the prevention of cancer. Public Health Nutrition 7, 187-200.
Lechner D, Kallay E \& Cross HS (2005) Phytoestrogens and colorectal cancer prevention. Vitamins and Hormones $\mathbf{7 0}$ 169-198.

Moller P, Vogel U, Pedersen A, Dragsted LO, Sandstrom B \& Loft S (2003) No effect of 600 grams fruit and vegetables per day on oxidative DNA damage and repair in healthy nonsmokers. Cancer Epidemiology, Biomarkers \& Prevention 12 1016-1022.

Nielsen IL, Dragsted LO, Ravn-Haren G, Freese R \& Rasmussen SE (2003) Absorption and excretion of black currant anthocyanins in humans and Watanabe heritable hyperlipidemic rabbits. Journal of Agricultural and Food Chemistry 51, 2813 2820.

Riboli E \& Norat T (2003) Epidemiologic evidence of the protective effect of fruit and vegetables on cancer risk. American Journal of Clinical Nutrition 78, 559S-569S.

Singh RB, Rastogi SS, Niaz MA, Ghosh S, Singh R \& Gupta S (1992a) Effect of fat-modified and fruit- and vegetableenriched diets on blood lipids in the Indian Diet Heart Study. American Journal of Cardiology 70, 869-874.

Singh RB, Sircar AR, Singh RG, Mani UV, Seth J \& Devi L (1992b) Dietary modulators of lipid metabolism in the Indian diet-heart study (I.D.H.S.). International Journal of Vitamin and Nutrition Research 62, 73-82.

Singhal S, Gupta R \& Goyle A (2001) Comparison of antioxidant efficacy of vitamin $\mathrm{E}$, vitamin $\mathrm{C}$, vitamin A and fruits in coronary heart disease: a controlled trial. Journal of the Association of Physicians India 49, 327-331.

Terpstra AH, Woodward CJ \& Sanchez-Muniz FJ (1981) Improved techniques for the separation of serum lipoproteins by density gradient ultracentrifugation: visualization by prestaining and rapid separation of serum lipoproteins from small volumes of serum. Analytical Biochemistry 111, $149-157$.

Vastag B (2005) Recent studies show limited association of fruit and vegetable consumption and cancer risk. Journal of the National Cancer Institute 97, 474-476.

Vogel U, Moller P, Dragsted L, Loft S, Pedersen A \& Sandstrom B (2002) Inter-individual variation, seasonal variation and close correlation of OGG1 and ERCC1 mRNA levels in full blood from healthy volunteers. Carcinogenesis 23, 1505-1509.

Young GP, Hu Y, Le Leu RK \& Nyskohus L (2005) Dietary fibre and colorectal cancer: a model for environment-gene interactions. Molecular Nutrition and Food Research 49, 571-584.

Young JF, Dragsted LO, Daneshvar B, Lauridsen ST, Hansen M \& Sandstrom B (2000) The effect of grape-skin extract on oxidative status. British Journal of Nutrition 84, 505-513.

Young JF, Dragsted LO, Haraldsdottir J, Daneshvar B, Kal MA, Loft $\mathrm{S}$ et al. (2002) Green tea extract only affects markers of oxidative status postprandially: lasting antioxidant effect of flavonoid-free diet. British Journal of Nutrition 87, 343-355.

Young JF, Nielsen SE, Haraldsdottir J, Daneshvar B, Lauridsen ST, Knuthsen P, Crozier A, Sandstrom B \& Dragsted LO (1999) Effect of fruit juice intake on urinary quercetin excretion and biomarkers of antioxidative status. American Journal of Clinical Nutrition 69, 87-94. 